\title{
Prestress Loss of CFL in a Prestressing Process for Strengthening RC Beams
}

\author{
Xinyan Guo, ${ }^{1}$ Dong Liu, ${ }^{1}$ Peiyan Huang, ${ }^{1,2}$ and Xiaohong Zheng ${ }^{1}$ \\ ${ }^{1}$ School of Civil Engineering and Transportation, South China University of Technology, Guangzhou 510640, China \\ ${ }^{2}$ State Key Laboratory of Building Science, South China University of Technology, Guangzhou 510640, China \\ Correspondence should be addressed to Xinyan Guo; xyguo@scut.edu.cn and Peiyan Huang; pyhuang@scut.edu.cn
}

Received 29 September 2016; Revised 13 January 2017; Accepted 20 April 2017; Published 9 May 2017

Academic Editor: Giuseppina Amato

Copyright (c) 2017 Xinyan Guo et al. This is an open access article distributed under the Creative Commons Attribution License, which permits unrestricted use, distribution, and reproduction in any medium, provided the original work is properly cited.

\begin{abstract}
A prestressing system was designed to strengthen reinforced concrete (RC) beams with prestressed carbon fiber laminate (CFL). During different prestressing processes, prestress loss was measured using strain gauges attached on the surface of CFL along the length direction. The prestress loss was $50-68 \%$ of the whole prestress loss, which is typically associated with CFL slipping between the grip anchors. Approximately $20-27 \%$ of the prestress loss was caused by the elastic shortening of the RC beam. An analytical model using linear-elastic theory was constructed to calculate the prestress loss caused by CFL slipping between the anchors and the elastic shortening of the strengthened beams. The compared results showed that the analytical model of prestress loss can describe the experimental data well. Methods of reducing the prestress loss were also suggested. Compared to other experiments, the prestressing system proposed by this research group was effective because the maximum percentage of prestress loss was $14.9 \%$ and the average prestress loss was $12.5 \%$.
\end{abstract}

\section{Introduction}

The application of bonded fiber-reinforced polymer (FRP) to the surfaces of concrete members provides an efficient, lightweight, and noncorrosive alternative to other repair methods. Although bonding nonprestressed FRP to reinforced concrete (RC) members can increase their ultimate bearing capacity, only a portion of the strength of FRP is utilized in nonprestressed strengthening systems. Furthermore, nonprestressed FRP strengthening techniques do not significantly change the cracking load of RC members. Compared to nonprestressed strengthening techniques, prestressing FRP can close cracks, delay the opening of new cracks, and restore prestress to a system that has suffered a loss of internal prestressing [1].

Currently, there are three prestressing systems that have been proposed for FRP strengthening technology. One method indirectly prestressed FRP sheets by cambering the flexural member [2]. Using this method, the levels of prestress generated in the FRP plate or sheet were low. The second method applied direct tension to FRP by jacking against an external reaction frame [3]. The prestressed FRP was bonded to an RC member with epoxy. When the epoxy resin was cured, the prestressing system was released. If the prestress level was high, additional anchoring was needed to be provided. The third method involved prestressing FRP by reacting it directly on a RC member [4]. A permanent mechanical anchorage system was fixed to the RC member, and the FRP sheets were prestressed directly by jacking and reacting against the $\mathrm{RC}$ member. After reaching the required prestress force, the movable anchors were locked, and the prestressed FRP sheets were bonded to the surface of the RC member.

For the first and second kinds of prestressing systems, in the prestressing process, after releasing the prestressed FRP plate, sheet, or laminate, high interfacial shear stress would generated at two ends of the FRP and would result in the FRP debonding. In the third method, because wave-shape grip anchors were directly installed on the strengthened beam, no high interfacial shear stress occurred. There were two arrangements on the end of the prestressed FRP before it was cut at both ends of the RC members. One was bolt anchorage [5]. The anchor bolts were fixed on the RC member to fasten 

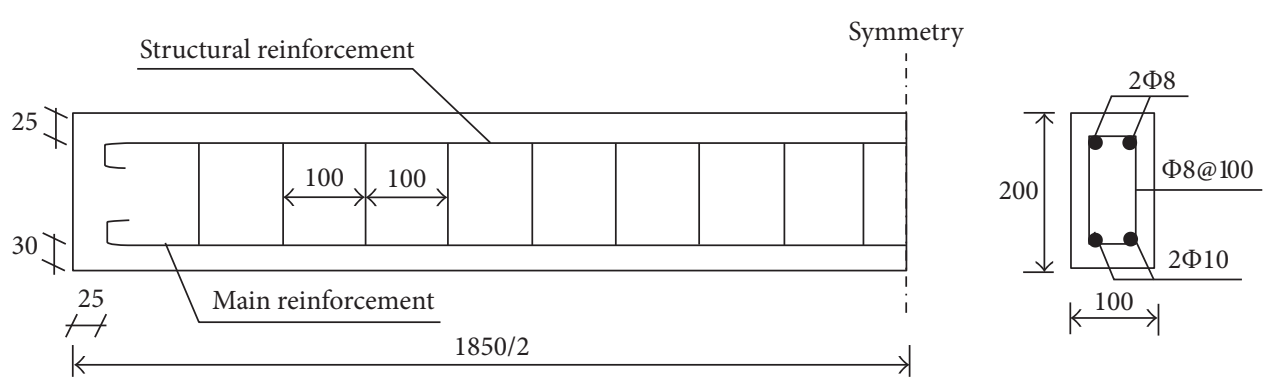

FIgURE 1: Steel bars used in an RC beam.

the FRP. The second arrangement was wrapping FRP around the RC member.

During the process of applying prestress to the plate, sheet, or laminate and bonding the prestressed FRP to an $\mathrm{RC}$ member, initial prestress loss was always generated $[6,7]$. Importantly, the actual prestress resulted when the external forces were released. However, currently, studies on prestress loss are limited. Garden and Hollaway [8] carried out an experimental study on strengthening RC beams using prestressed FRP plates. The plates were bonded with prestress levels ranging from $25 \%$ to $50 \%$ of the strength of the FRP plate. Prestressing was achieved using the second method described above and the nonanchored arrangement on the ends of the FRP plate. During the process of applying prestress to the plate and bonding the prestressed FRP plate to the RC beams, the prestress loss was influenced by the size of RC beams and the prestress level of the FRP applied. ElHacha et al. [2] used the third prestressing system described above to prestress FRP. The FRP composite materials used included CFRP plates and CFRP sheets, and the prestress levels ranged from $15 \%$ to $30 \%$ and $50 \%$ of the strength of the FRP plate. The percentages of prestress loss were recorded as ranging from $13.4 \%$ to $46.64 \%$. Diab et al. [9] utilized the second prestressing system to investigate rectangular beams bonded to prestressed FRP sheets, including anchored or unanchored FRP sheet ends. Using different layers of FRP sheet, the prestress levels of the FRP sheets varied from $21 \%$ to $40 \%$ of the tensile strength. The strains of the FRP sheets were measured when the FRP sheets were cut at both ends. Quantrill and Hollaway [3] carried out an experiment on strengthening RC beams using prestressed FRP plates with prestress levels ranging from $21.7 \%$ to $46.3 \%$ of their strength. The percentages of prestress loss were recorded as ranging from $26 \%$ to $40 \%$.

The prestress losses identified above were large, and longterm prestress loss was not measured.

Moreover, although the bolt anchorage arrangement can reduce shear stress and prestress loss [10], it to some extent caused damage to the RC members because some predrilled holes were used to fix the anchor bolts. It is important to choose a prestressed FRP strengthening method that does not cause secondary damage to concrete structures and determine the short- and long-term prestress loss laws of strengthened concrete members. In this paper, an experimental study was carried out to investigate the short- and longterm prestress loss law using the second prestressing system described above and the FRP wrapping arrangement at the ends of FRP. The results were compared to those reported by other researchers using different prestressing system and different arrangement on the ends of FRP.

\section{Experimental Program}

2.1. Test Materials and Specimens. A total of fifteen specimens were designed for this study. The typical geometry and reinforcement of the tested beams are shown in Figure 1. The size of the RC beams was $1850 \mathrm{~mm}$ length $\times 100 \mathrm{~mm}$ width $\times 200 \mathrm{~mm}$ height. The composition proportion of concrete was $m_{c}: m_{w}: m_{s}: m_{a}=1.0: 0.5: 2.06: 3.66$ (cement: water : sand : gravel). The cube compressive strength and the elastic modulus of the concrete were $53.3 \mathrm{MPa}$ and 35.2 GPa, respectively. The main steel bars exhibited a yield strength of $307 \mathrm{MPa}$ and an elastic modulus of $206 \mathrm{GPa}$. In this paper, the RC beams were strengthened with prestressed carbon fiber laminate (CFL) [11] as the specimens. The CFL used in this paper was knitted by unidirectional carbon fiber silk and epoxide resin, which possessed the combined advantages of carbon fiber sheets and plates. The size and thickness of CFL can be determined and knitted according to the project requirements and reduce the effect of multilayer bonding. The elastic modulus of the CFL was $230 \mathrm{GPa}$ with an ultimate tensile strength of $4750 \mathrm{MPa}$. The width of CFL was $100 \mathrm{~mm}$, and the normal thickness was $0.23 \mathrm{~mm}$. The adhesive used between concrete and CFL was A and B epoxy adhesive. The thickness of the A and B epoxy adhesive layer was in total approximately $0.2 \mathrm{~mm}$, and most of the adhesive penetrated into the concrete. The shear strength of the epoxy adhesive was $14 \mathrm{MPa}$.

In total, 15 beams were divided into three groups based on the three different levels of prestress applied to CFL. Each group consisted of five strengthened beams. The three groups were strengthened by CFL with the prestress levels of $8 \%, 15 \%$, or $22 \%$ with the CFL wrapping arrangement on the ends of CFL.

2.2. Prestressing System. A prestressing system for stretching CFL and strengthening RC beams was designed and constructed by our research group as shown in Figures 2 and 3. In this prestressing system, CFL was placed between two movable wave-shape grip anchors. The target RC beam was positioned under the prestressing bed. The prestressing system consisted of a stiff steel frame, movable wave-shape 


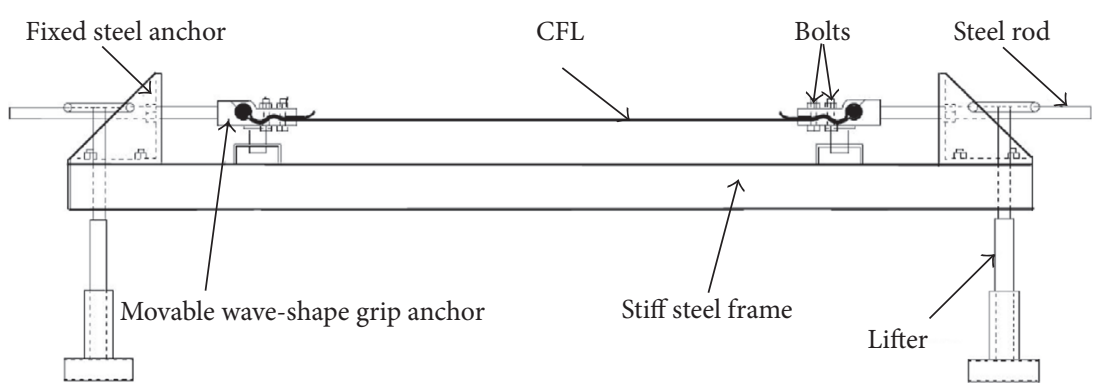

FIGURE 2: Bed of the prestressing system.

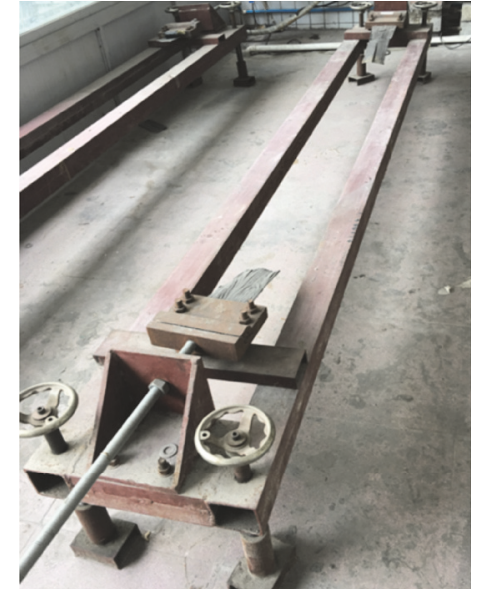

Figure 3: Photo of prestressing system.

grip anchor, fixed steel anchor, steel rod, and hydraulic jack. One roller and two wave-shape steels were set up in the movable wave-shape grip anchor. CFL was wrapped around the roller, and the two wave-shape steels were fastened by four bolts. The fixed steel anchors were welded to the end of frame to prevent any possible bending due to prestressing. The steel rods were inserted through the holes in both the movable wave-shape grip anchor and the fixed steel anchor and used at the jacking end. The CFL was prestressed by jacking and reacting against the stiff steel frame. The tensile loads and strains of CFL were measured by load cells and strain gauges attached along the length of the CFL. The lifter was used to adjust the height of the prestressing bed. It should be noted that the dimensions of all components of the anchorage system were based on finite-element analysis and several tests.

2.3. Prestressing and Bonding of CFL. The method of strengthening RC beams with prestressed CFL is illustrated in Figure 4 and summarized as follows:

(1) The concrete surface was prepared using a sander to remove the cement cover and cleaned with acetone. Then, the beam was positioned near the prestressing bed.

(2) The prestressing bed was hoisted to enable easy operation. The CFL was placed between the movable wave-shape grip anchors, and the bolts were used to fasten the grip anchors.

(3) By pumping oil into the hydraulic jack, the movable wave-shape grip anchors moved forward in the direction of the fixed steel anchor and exerted tensile force on CFL. CFL was pretensioned to $2.4 \%$ of its strength, and the loose nut was rotated until it locked the movable anchor in place. The bolts on the movable anchor were fastened to reduce the gap of the anchor, and then the loose nut was rotated opposite direction to release the prestressing load. The operating step is shown in Figure 4(a)

(4) A and B epoxy adhesive was brushed on the surface of the beam with a spatula as shown in Figure 4(b).

(5) The CFL was prestressed again, and the movable anchor was locked when the tensile load reached the desired prestressing force. In this study, three prestress levels $(8 \%, 15 \%$, and $22 \%)$ were used.

(6) The RC beam was moved under the prestressing bed as shown in Figure 4(c).

(7) The lifter was lowered down, and the prestressed CFL was bonded to the surface of the concrete. CFL was wrapped and bonded to the two ends of the strengthened RC beam as shown in Figure 4(d). After 5-7 days of curing time, the applied prestress was gradually alleviated by releasing the hydraulic jacks, and then the CFLs were cut at both ends.

The whole procedure of the prestressing and bonding of CFL was divided into four steps: tension, bonding, curing, and release.

2.4. Strain Measurement. Before loading the prestressing force, strain gauges were attached on the middle and quarter of CFL in the length direction. To monitor the effect of CFL wrapping, 28 strain gauges were attached near the corner of the wrap before the prestressing force was released. The distribution of the strain gauges on the CFL wrapping is shown in Figure 5. The strain gauges on the prestressed CFL and CFL wrapping were connected to a data acquisition system to measure and record the strains during the whole prestressing process.

The details of the experimental conditions are shown in Table 1. 


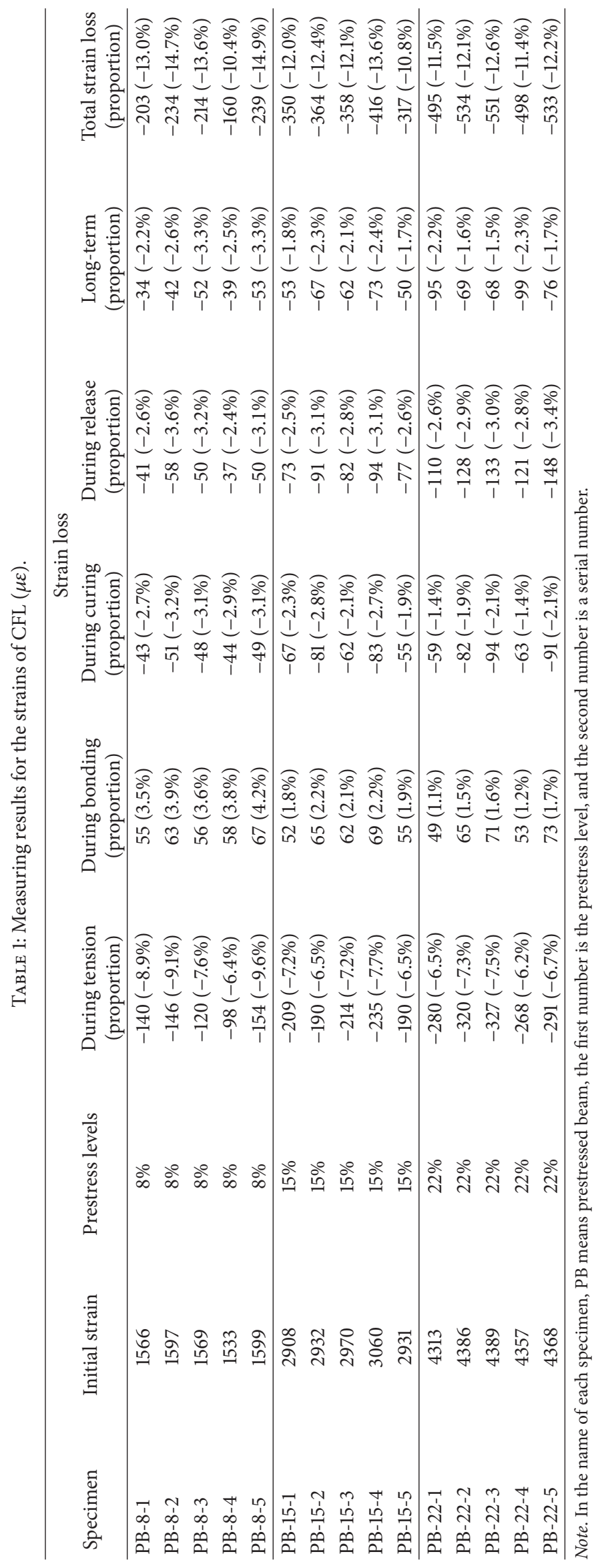




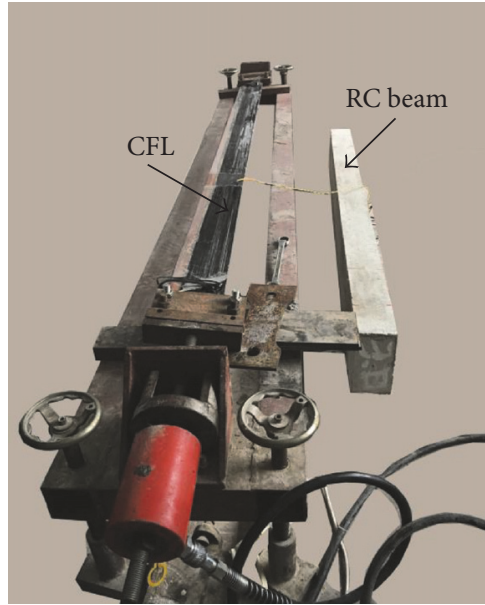

(a) Prestressing CFL

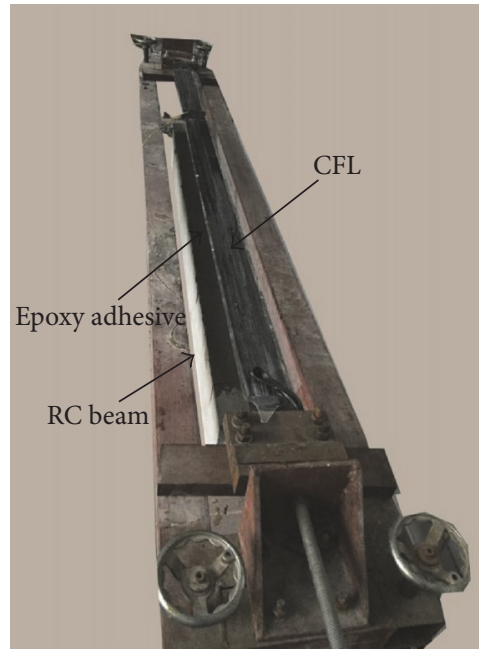

(c) Moving the RC beam under the prestressing bed

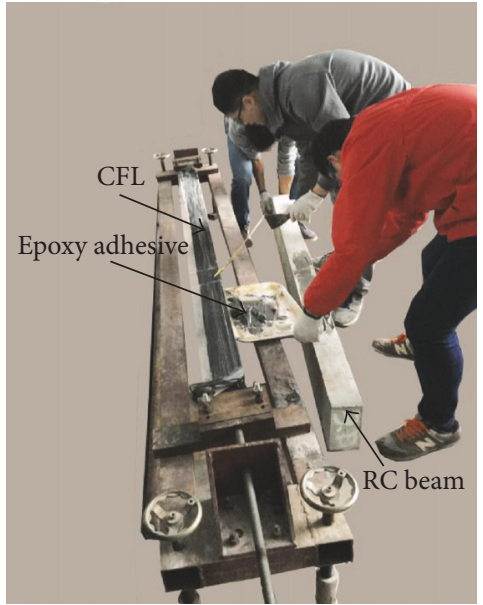

(b) Brushing the epoxy adhesive

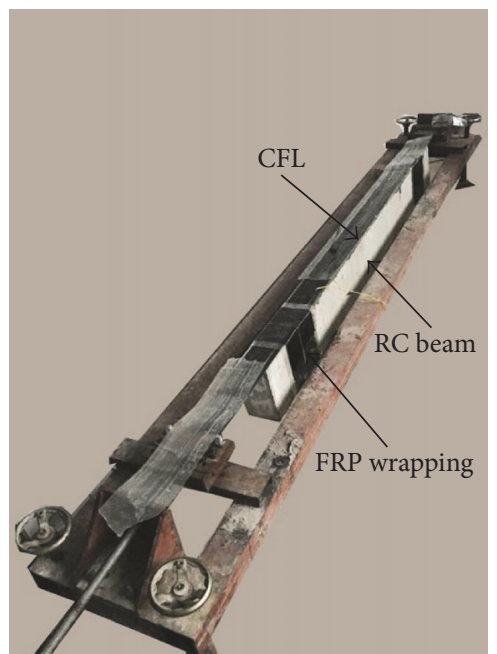

(d) Bonding and wrapping CFL

FIGURE 4: Strengthening method with prestressed CFL for RC beams.

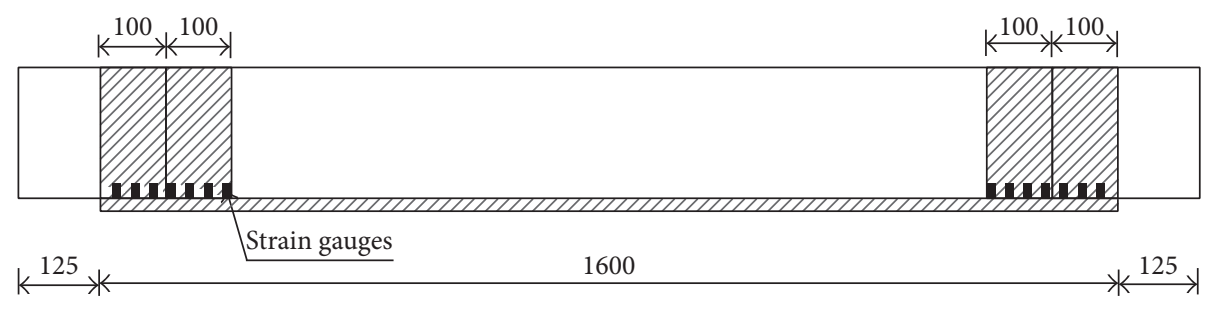

FIGURE 5: CFL wrapping and strain gauges.

\section{Experimental Results and Discussions}

After releasing the prestressed CFL, the prestressing force was transferred to the RC beam. The experimental investigation includes the short-term and long-term behavior of the bonding performance of prestressed CFL. Typically, the short-term was defined as immediate responses of CFL when the prestressing force was transferred, and the long-term behavior included those up to 30 days.

The strain measurement results used for calculating the prestress loss of CFL are shown in Table 1.

3.1. Prestress Loss during Tension. As shown in Table 1, prestress loss was significant during the prestressing process. 


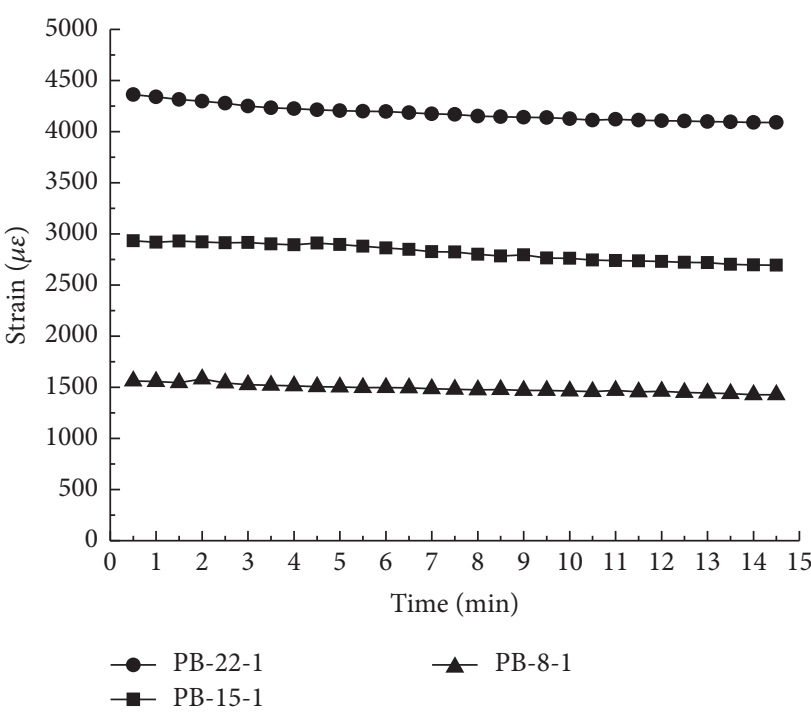

(a) Strain variations of CFL during tension

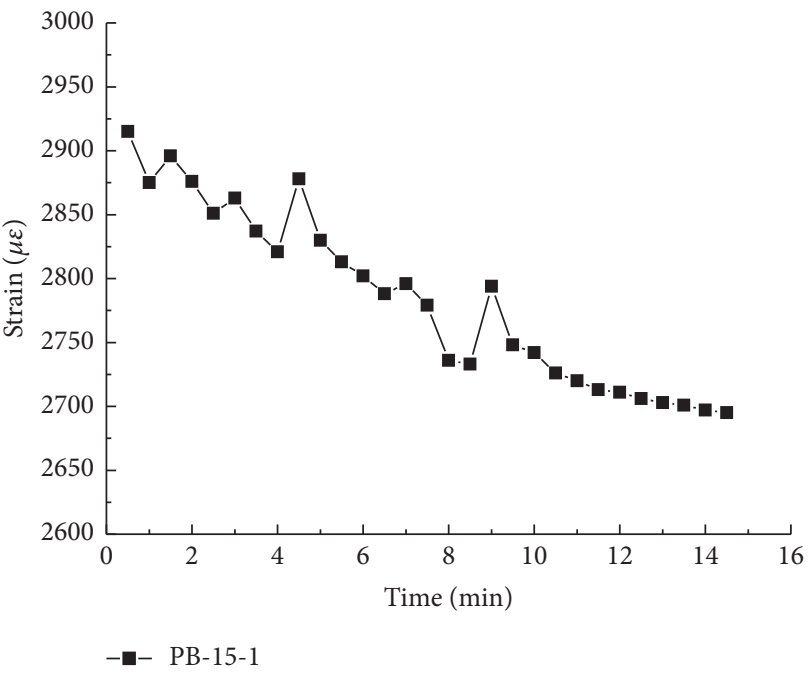

(b) Strain variation of CFL during tension (PB-15-1)

FIGURE 6: Strain variations of CFL during tension.

There were two main reasons that caused the noticeable prestress loss. One was deflection of the anchor when the hydraulic jack was released from the steel rod. The second was CFL slipping between the movable wave-shape grip anchors.

Figure 6(a) shows the changes in strain on CFL during the application of tension. Three groups of specimens were strengthened by CFL with the prestress levels of $8 \%, 15 \%$, and $22 \%$. The strain variation of CFL on specimen PB- $15-1$ is plotted in Figure 6(b). As shown in Table 1 and Figure 6, the prestress loss during tension was higher when the CFL was tensioned at a higher prestress level, but the relative prestress loss decreased as the prestress level increased.

3.2. Prestress Increase during Bonding. When the loading reached the desired prestressing force, the lifter was lowered and the prestressed CFL was bonded to the surface of the RC beam. During bonding, downward forces were applied to CFL to ensure that it bonded closely, which led to an increase in strain increment of prestressed CFL. During the test, the lifter was lowered down, and the CFL was moved as close to the surface of beam as possible. The strain increment was not relevant to the prestress levels and was influenced by the thickness of layer of epoxy adhesive between the CFL and the surface of the beam. The strain variation of CFL on specimen PB-15-1 is plotted in Figure 7.

3.3. Prestress Loss during Curing. After 5-7 days, the epoxy adhesive between the prestressed CFL and the surface of the $\mathrm{RC}$ beam was cured. The prestress loss during curing was caused by slipping between the CFL and the movable waveshape grip anchor. The strain loss increased slightly as the prestress level increased and was generated during the first 10 hours of the curing process. The strain changes on CFL during the curing are shown in Figure 8.

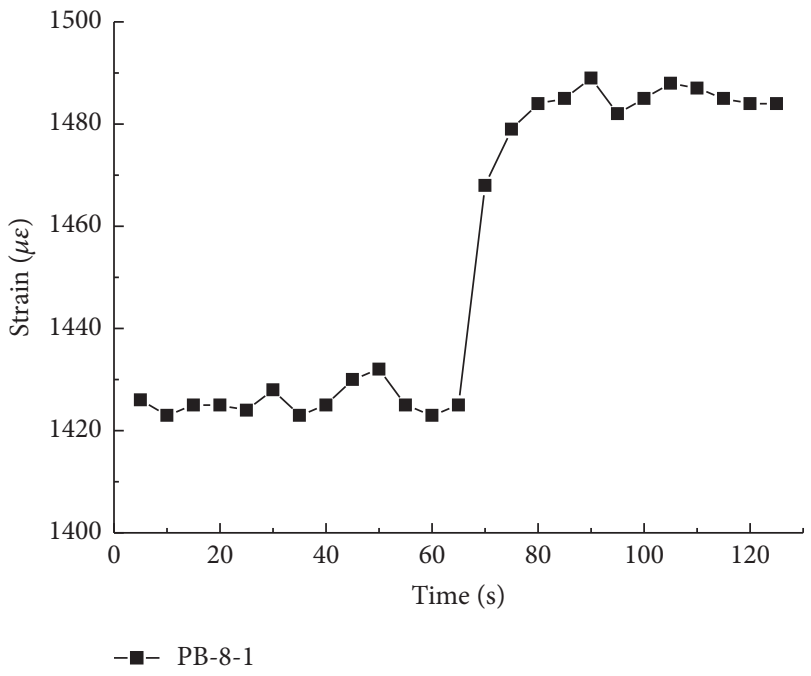

FIGURE 7: Strain variation of CFL during bonding.

3.4. Prestress Loss during Release. The last step of the prestressing operation was releasing the prestressing system. During the release, the applied prestress was gradually alleviated by releasing the hydraulic jacks, and then the CFL was cut at both ends. After releasing the prestressed CFL, the prestressing force was transferred to the $\mathrm{RC}$ beam. The prestress loss during the releasing step was caused by the elastic shortening of the RC beam, and the strain changes in CFL during this step under the three different prestress levels (8\%, 15\%, and 22\%) are shown in Figure 9(a). The strain variation of CFL on the specimen PB-15-1 during the release is plotted in Figure 9(b). As shown in Table 1 and Figure 9, the prestress loss during the release step was higher when the CFL 


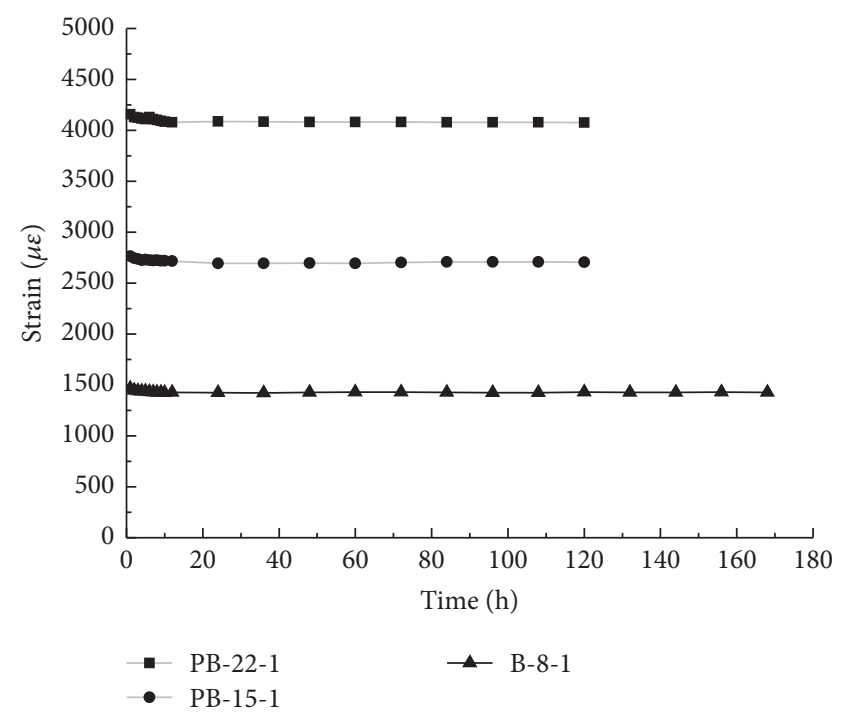

(a) Strain variations of CFL during curing

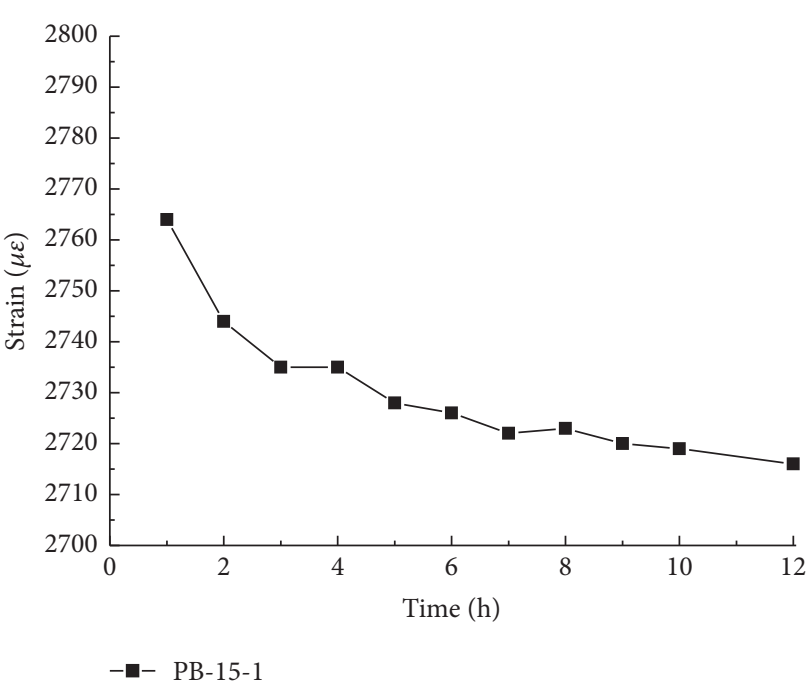

(b) Strain variation of CFL during curing (PB-15-1)

FIGURE 8: Strain variations of CFL during curing.

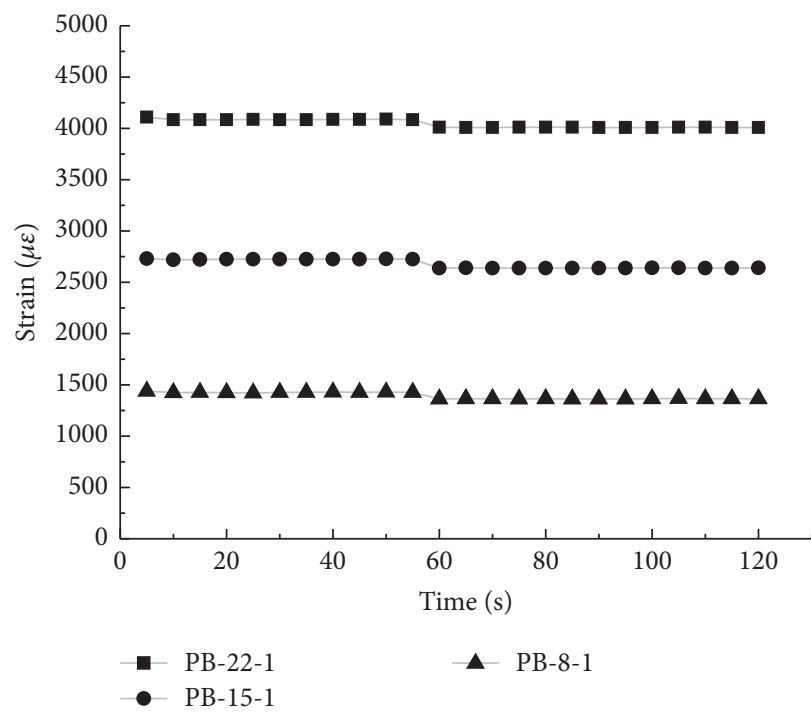

(a) Strain variations of CFL during release

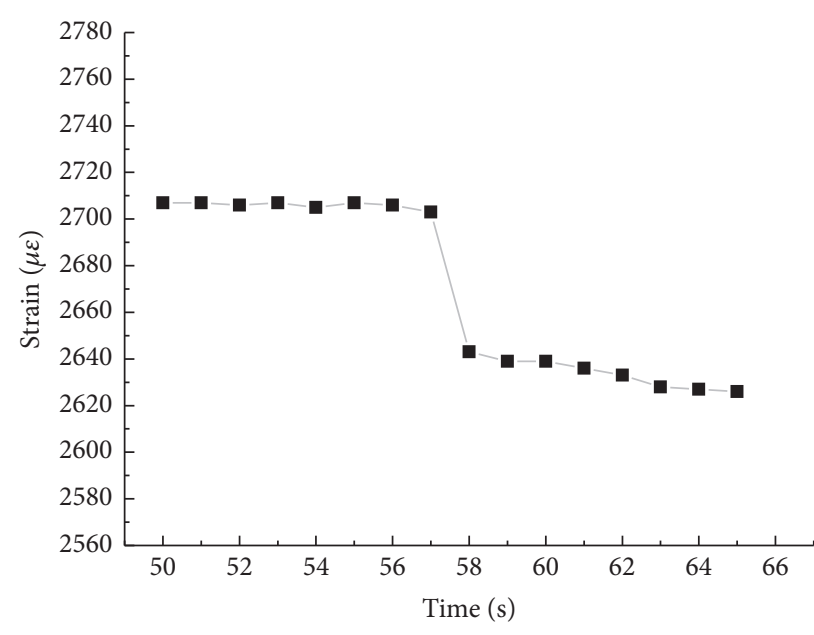

- $\mathrm{PB}-15-1$

(b) Strain variation of CFL during release (PB-15-1)

FIGURE 9: Strain variations of CFL during release.

was tensioned with a higher prestress level, but the relative prestress loss decreased as the prestress level increased.

3.5. Long-Term Prestress Loss. After release, the strain gauges on CFL were still connected to the data acquisition system to continue recording the strain. The monitoring periods were 21 and 30 days. The prestress loss in the long term was still due to the elastic shortening of the RC beam, as shown in Figure 10(a), with the three prestress levels $(8 \%, 15 \%$, and $22 \%)$. The strain variation of CFL on the specimen PB-15-1 during the first day is plotted in Figure 10(b). As shown in Table 1 and Figure 10, the prestress loss in the long term was slightly higher when the CFL was tensioned with a higher prestress level and generated during the first 5 days.

3.6. Strains on CFL Wrapping. After releasing the hydraulic jacks and cutting CFL at both ends, the maximum strain on the CFL wrapping was approximately $160 \mu \varepsilon$, which was obtained at the end of the CFL in the length direction (Figure 5). The strain on the CFL wrapping gradually decreased when the strain gauge was far from the end of the CFL in the length direction. At a distance of $125 \mathrm{~mm}$ from the end of the CFL in the length direction, the strain on the CFL wrapping was zero. 
TABLE 2: Prestress loss by predictions and measurements during tension.

\begin{tabular}{lccccc}
\hline Specimens & Prestress levels/\% & $\Delta l_{1} / \mathrm{mm}$ & $\begin{array}{c}\text { Predicted prestress } \\
\text { loss/MPa }\end{array}$ & $\begin{array}{c}\text { Measured prestress } \\
\text { loss/MPa }\end{array}$ & Relative errors/\% \\
\hline PB-8 & 8 & 0.4 & 34.28 & 33.17 & 1.033 \\
PB-15 & 15 & 0.6 & 51.43 & 50.16 & 1.025 \\
PB-22 & 22 & 0.8 & 69.57 & 68.66 & 1.013 \\
\hline
\end{tabular}

Note. PB-8 are prestressed-CFL-strengthened RC beams with $8 \%$ prestress level.

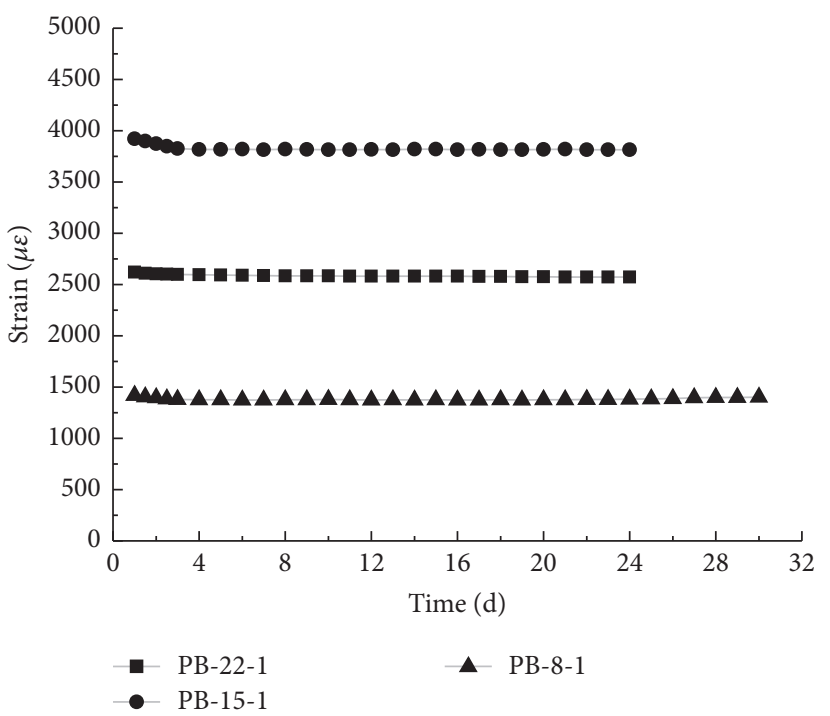

(a) Strain variations of CFL in the 30 days after release

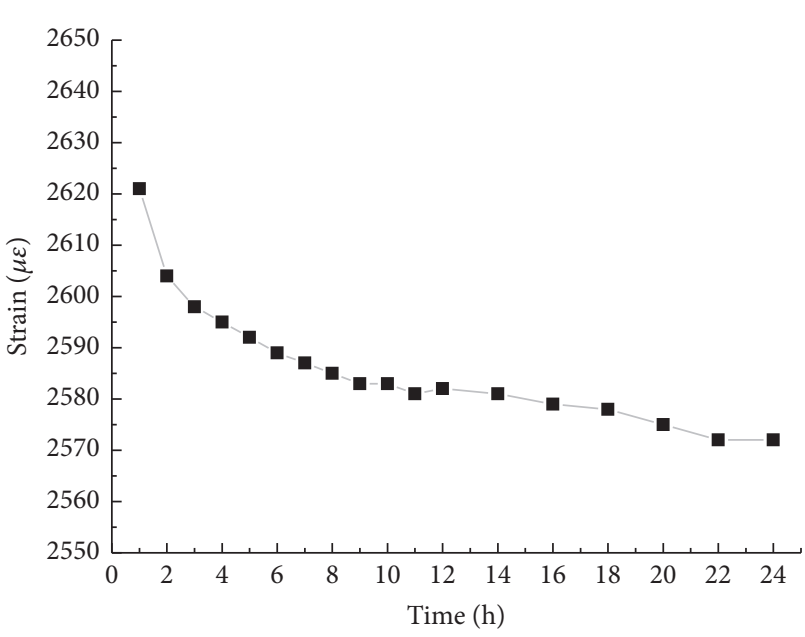

- PB-15-1

(b) Strain variation of CFL (PB-15-1) during the first day

FIgURE 10: Long-term strain variations of CFL after release.

\section{Analytical Model of Prestress Loss}

As shown in Table 1, during the process of applying prestress to CFL and bonding the prestressed CFL to RC beams, the majority of prestress loss was caused by CFL slipping between the movable wave-shape grip anchors and the elastic shortening of the RC beam. Between these two, the prestress loss caused by the CFL slip was $50-68 \%$ of the whole prestress loss, while $20-27 \%$ of the whole prestress loss was caused by the elastic shortening of the RC beam. Therefore, it was necessary to calculate the prestress loss caused by the CFL slip during tension and elastic shortening of the RC beam after releasing.

4.1. Calculation of Prestress Loss during Tension. Before loading the prestress force, CFL was wrapped around the roller and sandwiched between the movable anchors. Four bolts were tightened to provide frictional resistance to the anchor. During the tension, CFL slipping was caused by a small amount of deformation of the prestressing bed and the gap between the two anchors.

Considering the above causes, which would lead to prestress loss of CFL, and based on the code of (JTG
D62-2012) [12], the prestress loss during tension, $\sigma_{l s l i p}(\mathrm{MPa})$, can be calculated as follows:

$$
\sigma_{l \mathrm{slip}}=\frac{\Delta l_{1} \cdot E_{\mathrm{cf}}}{l}
$$

where $\Delta l_{1}, E_{\mathrm{cf}}$, and $l$ are the slip deformation during tension, the elastic modulus of CFL, and the distance between the two fixed steel anchors, respectively. The total deformation during tension was a combination of the CFL slip and deformation of the prestressing bed. The CFL slip value was influenced by several factors, such as the friction coefficient between the CFL and the anchor, the bolt pressure on the anchor, and the area between the CFL and the anchor.

The code of (JTG D62-2012) suggests that if the prestressed material is steel, the value of $\Delta l_{1}$ is taken as $1 \mathrm{~mm}$. Because prestressed CFL displays little elongation, the value of $\Delta l_{1}$ was taken as $0.2-1 \mathrm{~mm}$, depending on the prestress level.

In the tests, the distance of two fixed steel anchors $l$ was measured as $2800 \mathrm{~mm}$. The elastic modulus of CFL $\left(E_{\mathrm{cf}}\right)$ was $230 \mathrm{GPa}$. Substituting these parameters into formula (1) allows the prestress loss of CFL during tension to be calculated. The comparison of the calculated results to the experimental data is shown in Table 2 and revealed that 


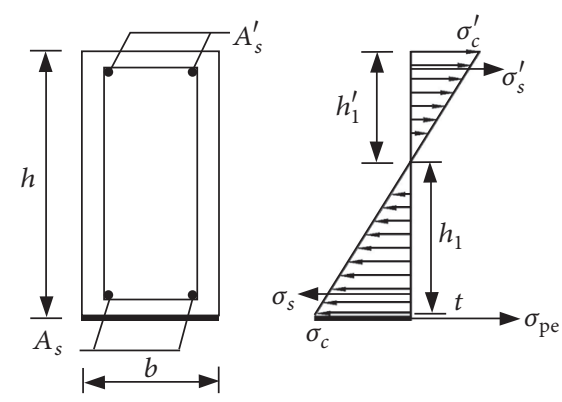

FIGURE 11: Stress distribution on cross-section of the RC beam after releasing.

the predicted values for prestress loss and measured values coincided well. The relative errors were approximately $1 \%$.

To reduce the prestress loss caused by CFL slipping and deformation of the anchor system, some measures should be taken: (1) increasing the friction coefficient between CFL and the anchor; (2) applying pretension to CFL at 2-3\% of its strength before loading the prestress force and rotating the loose nut until it locks the movable anchor in place; (3) fastening the bolts on the movable anchor to reduce the gap of the movable anchor and the prestress loss; and (4) increasing the rigidity of the prestressing bed and anchor system.

4.2. Calculation of Prestress Loss after Releasing. The following derivation of the prestress loss caused by elastic shortening of the RC beam was made for a beam with typical rectangular cross-section, but the method of this analysis is also applicable to any beam with arbitrary cross-sections and material properties, providing the same assumption holds.

When prestressed CFL was bonded on a RC beam and the epoxy resin was cured for several days, the prestress force was released and CFL was cut at both ends. After the release, the RC beam was assumed to be linear elastic. Figure 11 shows a stress distribution on a cross-section of an $\mathrm{RC}$ beam strengthened with prestressed CFL after release. The equilibrium requires that

$$
\begin{gathered}
\sigma_{\mathrm{pe}} A_{\mathrm{cf}}+\int_{0}^{h_{1}^{\prime}} \frac{\sigma_{c}^{\prime}}{h_{1}^{\prime}} b x d x+\sigma_{s}^{\prime} A_{s}^{\prime}+\int_{-h_{1}}^{0} \frac{\sigma_{c}}{h_{1}} b x d x \\
-\sigma_{s} A_{s}=0 \\
\sigma_{\mathrm{pe}} A_{\mathrm{cf}}\left(h_{1}+\frac{t}{2}\right)-\int_{0}^{h_{1}^{\prime}} \frac{\sigma_{c}^{\prime}}{h_{1}^{\prime}} b x^{2} d x-\sigma_{s}^{\prime}\left(h_{1}^{\prime}-a\right) A_{s}^{\prime} \\
-\int_{-h_{1}}^{0} \frac{\sigma_{c}}{h_{1}} b x^{2} d x-\sigma_{s}\left(h_{1}-a\right) A_{s}=0,
\end{gathered}
$$

where $\sigma_{c}$ and $\sigma_{c}^{\prime}$ are the tensile and compressive stress of concrete; $\sigma_{s}$ and $\sigma_{s}^{\prime}$ are the tensile and compressive stress of a steel bar; $\sigma_{\mathrm{pe}}$ is the effective stress of CFL after releasing the prestress force; $h_{1}$ and $h_{1}^{\prime}$ are the height of the tensile and compressive parts of the beam; $t$ is the computed thickness of CFL; $b$ and $h$ are width and height of the beam; $A_{s}$ and $A_{s}^{\prime}$ are the cross-sectional areas of tensile and compressive steel bars; $a$ is the thickness of the concrete protective cover, and $A_{\mathrm{cf}}$ is the cross-sectional area of CFL.

Considering the compatibility of stress distribution, the normal stress of the steel bar and concrete can be obtained as follows:

$$
\begin{aligned}
& \sigma_{s}^{\prime}=\sigma_{c}^{\prime} \frac{h_{1}^{\prime}-a}{h_{1}^{\prime}} \frac{E_{s}}{E_{c}} \\
& \sigma_{s}=\sigma_{c} \frac{h_{1}-a}{h_{1}} \frac{E_{s}}{E_{c}} \\
& \frac{\sigma_{c}^{\prime}}{\sigma_{c}}=\frac{h_{1}^{\prime}}{h_{1}}=\beta,
\end{aligned}
$$

where $E_{s}$ and $E_{c}$ are the elastic modulus of the steel bar and concrete, respectively. Let

$$
\alpha_{E}=\frac{E_{s}}{E_{c}}
$$

If the thickness of CFL, $t$, is assumed to be negligible in comparison to the height of the strengthened beam, the effective stress of CFL, $\sigma_{\text {pe }}$, can be found as follows:

$$
\sigma_{\mathrm{pe}}=\frac{\sigma_{c}}{A_{\mathrm{cf}}}\left[\frac{b h}{2}(1-\beta)+\alpha_{E} A_{s}\left(1-\frac{1+\beta}{h} a\right)\right] .
$$

Thus, the prestress loss, $\sigma_{\mathrm{ls}}$, caused by the elastic shorting of the RC beam was

$$
\sigma_{\mathrm{ls}}=\sigma_{\mathrm{pf}}-\sigma_{\mathrm{pe}}
$$

where $\sigma_{\mathrm{pf}}$ is the prestress on CFL before release.

Considering the compatibility of deformation, the reduction strain of CFL, $\Delta \varepsilon_{\mathrm{pf}}$, is assumed to be

$$
\Delta \varepsilon_{\mathrm{pf}}=\Delta \varepsilon_{c},
$$

where

$$
\begin{aligned}
\Delta \varepsilon & =\frac{\sigma_{c}}{E_{c}} \\
\Delta \varepsilon_{\mathrm{pf}} & =\frac{\sigma_{l}}{E_{\mathrm{cf}}},
\end{aligned}
$$

where $\Delta \varepsilon_{c}$ is the strain increment of concrete; $E_{\mathrm{cf}}$ is the elastic modulus of CFL; and $E_{c}^{\prime}$ is the equivalent elastic moduli of concrete and steel.

$$
E_{c}^{\prime}=E_{s} \mu+E_{c}(1-\mu),
$$

where $\mu$ is the reinforcement ratio of the concrete beam.

$$
\mu=\frac{A_{s}+A_{s}^{\prime}}{b h} .
$$

From (5) to (10), the ratio $\left(\sigma_{l} / \sigma_{\mathrm{pf}}\right)$ of prestress loss caused by elastic shortening of the RC beam to the prestress on CFL 
TABLE 3: Prestress loss by predictions and experiments after releasing.

\begin{tabular}{|c|c|c|c|c|c|c|c|c|}
\hline \multirow[t]{2}{*}{ Authors } & \multirow[t]{2}{*}{ Size of RC beam $/ \mathrm{mm}$} & \multirow{2}{*}{$E_{c} / \mathrm{GPa}$} & \multirow{2}{*}{$E_{s} / \mathrm{GPa}$} & \multirow{2}{*}{$E_{\mathrm{cf}} / \mathrm{GPa}$} & \multirow{2}{*}{$t / \mathrm{mm}$} & \multirow{2}{*}{$\sigma_{\mathrm{pf}} / \mathrm{MPa}$} & \multicolumn{2}{|c|}{$\sigma_{l} / \sigma_{\mathrm{pf}}$} \\
\hline & & & & & & & $\begin{array}{c}\text { Calculating values } \\
\text { by (11) }\end{array}$ & $\begin{array}{c}\text { Experimental } \\
\text { values }\end{array}$ \\
\hline \multirow[t]{2}{*}{ Quantrill and Hollaway [3] } & \multirow[t]{2}{*}{$1000 \times 100 \times 100$} & \multirow{2}{*}{34} & \multirow{2}{*}{220} & \multirow{2}{*}{135} & \multirow[t]{2}{*}{1.3} & 221.13 & $8.3 \%$ & $7.1 \%$ \\
\hline & & & & & & 343.44 & $8.3 \%$ & $9.5 \%$ \\
\hline \multirow{3}{*}{ This paper } & \multirow{3}{*}{$1850 \times 100 \times 200$} & \multirow{3}{*}{35.2} & \multirow{3}{*}{206} & \multirow{3}{*}{230} & \multirow{3}{*}{0.23} & 380.0 & $2.1 \%$ & $3.0 \%$ \\
\hline & & & & & & 712.5 & $2.1 \%$ & $2.8 \%$ \\
\hline & & & & & & 1045.0 & $2.1 \%$ & $2.9 \%$ \\
\hline
\end{tabular}

before release can be obtained by the equation

$$
\frac{\sigma_{l}}{\sigma_{\mathrm{pf}}}=\frac{t \lambda}{t \lambda+(h / 2)(1-\beta)+\left(\alpha_{E} A_{s} / b\right)(1-((1+\beta) / h) a)-\left(\alpha_{E} A_{s}^{\prime} / b\right)(\beta-((1+\beta) / h) a)}
$$

where $\lambda=E_{\mathrm{cf}} / E_{c}$.

To verify the analytical model (11), the experimental data obtained by Quantrill and Hollaway [3] and the experimental results of this paper were analyzed and listed in Table 3.

The comparison between the two showed that the analytical model of prestress loss caused by the elastic shortening of the RC beam after release was in good agreement with the experimental data. However, it should be noted that error may be created by assumptions. In the derivation, the mechanical properties of all materials of the strengthened beam were assumed to be linear elastic. If the initial prestress was higher, then the concrete might show plastic behavior, thus requiring the model derived in this paper to be modified. The error was also influenced by strain measure. The CFL used in this paper was knitted by unidirectional carbon fiber silk and epoxide resin. The force on the CFL was not even absolutely during prestressing procedure. The assumptions and the strain measure were the main causes of the error between the calculating and experimental values.

\section{Conclusions}

A prestressing system for strengthening RC beams with prestressed CFL was designed. Prestress loss of CFL in the prestressing process of strengthened RC beams was measured. The results of this study were analyzed, and the following conclusions were obtained:

(1) Prestress loss was measured during the whole prestressing test. The measured results showed that maximum prestress loss of CFL was $14.9 \%$ and that the majority of prestress loss was caused by CFL slipping between the movable wave-shape grip anchors and the elastic shortening of the RC beam. The prestress loss caused by the CFL slip between the grip anchors was $50-68 \%$ of the whole prestress loss, while $20-27 \%$ of the whole prestress loss was caused by the elastic shortening of the RC beam.

(2) An analytical model for calculating the prestress loss was established. The results showed that the calculated prestress loss caused by elastic shortening of the RC beam after releasing was in good agreement with the experimental data. The initial prestress was found to have a great effect on the prestress loss caused by the elastic shortening of the RC beam after release, but the ratio $\left(\sigma_{l} / \sigma_{\mathrm{pf}}\right)$ of prestress loss caused by elastic shortening of the RC beam to the initial prestress was constant.

(3) A prestressing system and prestress loss measuring method were designed and constructed. Comparing these to other systems and measurement methods of prestress loss of RC members strengthened with CFL showed that the proposed prestressing system and prestress loss measuring method were more effective and convenient.

It should be noted that the RC beam was assumed to be linear elastic and all materials behaved linearly elastically in the analytical model. If the initial prestress was higher, then the concrete would behave plastically, and the model would have to be modified.

\section{Conflicts of Interest}

The authors declare that they have no conflicts of interest.

\section{Acknowledgments}

The project is supported by the National Natural Science Foundation of China (nos. 11627802, 51678249, 11132004, and 51508202) and Natural Science Foundation of Guangdong Province (no. 2016A030310414). 


\section{References}

[1] R. G. Wight, M. F. Green, and M.-A. Erki, "Prestressed FRP sheets for poststrengthening reinforced concrete beams," Journal of Composites for Construction, vol. 5, no. 4, pp. 214-220, 2001.

[2] R. El-Hacha, R. G. Wight, and M. F. Green, "Prestressed fibrereinforced polymer laminates for strengthening structures," Progress in Structural Engineering and Materials, vol. 3, pp. 111121, 2001.

[3] R. J. Quantrill and L. C. Hollaway, “The flexural rehabilitation of reinforced concrete beams by the use of prestressed advanced composite plates," Composites Science and Technology, vol. 58, no. 8, pp. 1259-1275, 1998.

[4] R. El-Hacha and M. Y. E. Aly, "Anchorage system to prestress FRP laminates for flexural strengthening of steel-concrete composite girders," Journal of Composites for Construction, vol. 17, no. 3, pp. 324-335, 2013.

[5] Q. Cao, J. Tao, and Z. J. Ma, "Prestress loss in externally FRP reinforced self prestressing concrete beams," Construction and Building Materials, vol. 101, pp. 667-674, 2015.

[6] W.-W. Wang, J.-G. Dai, K. A. Harries, and Q.-H. Bao, "Prestress losses and flexural behavior of reinforced concrete beams strengthened with posttensioned CFRP sheets," Journal of Composites for Construction, vol. 16, no. 2, pp. 207-216, 2012.

[7] I. Costa and J. Barros, "Prestress losses in nsm-cfrp flexurally strengthened rc beams," Strain, vol. 51, no. 4, pp. 276-287, 2015.

[8] H. N. Garden and L. C. Hollaway, "An experimental study of the failure modes of reinforced concrete beams strengthened with prestressed carbon composite plates," Composites Part B: Engineering, vol. 29, no. 4, pp. 411-424, 1998.

[9] H. Diab, Z. Wu, and K. Iwashita, "Short and long-term bond performance of prestressed FRP sheet anchorages," Engineering Structures, vol. 31, pp. 1241-1249, 2009.

[10] A. Abdullah, C. G. Bailey, and Z. J. Wu, "Tests investigating the punching shear of a column-slab connection strengthened with non-prestressed or prestressed FRP plates," Construction and Building Materials, vol. 48, pp. 1134-1144, 2013.

[11] Y. P. Huang and J. C. Zeng, "Carbon fiber laminate and its application," China Patent Administration, 2006.

[12] JTG D62-2012: Code for design of highway reinforce concrete and prestressed concrete bridges and culverts. Beijing, China, 2012. 

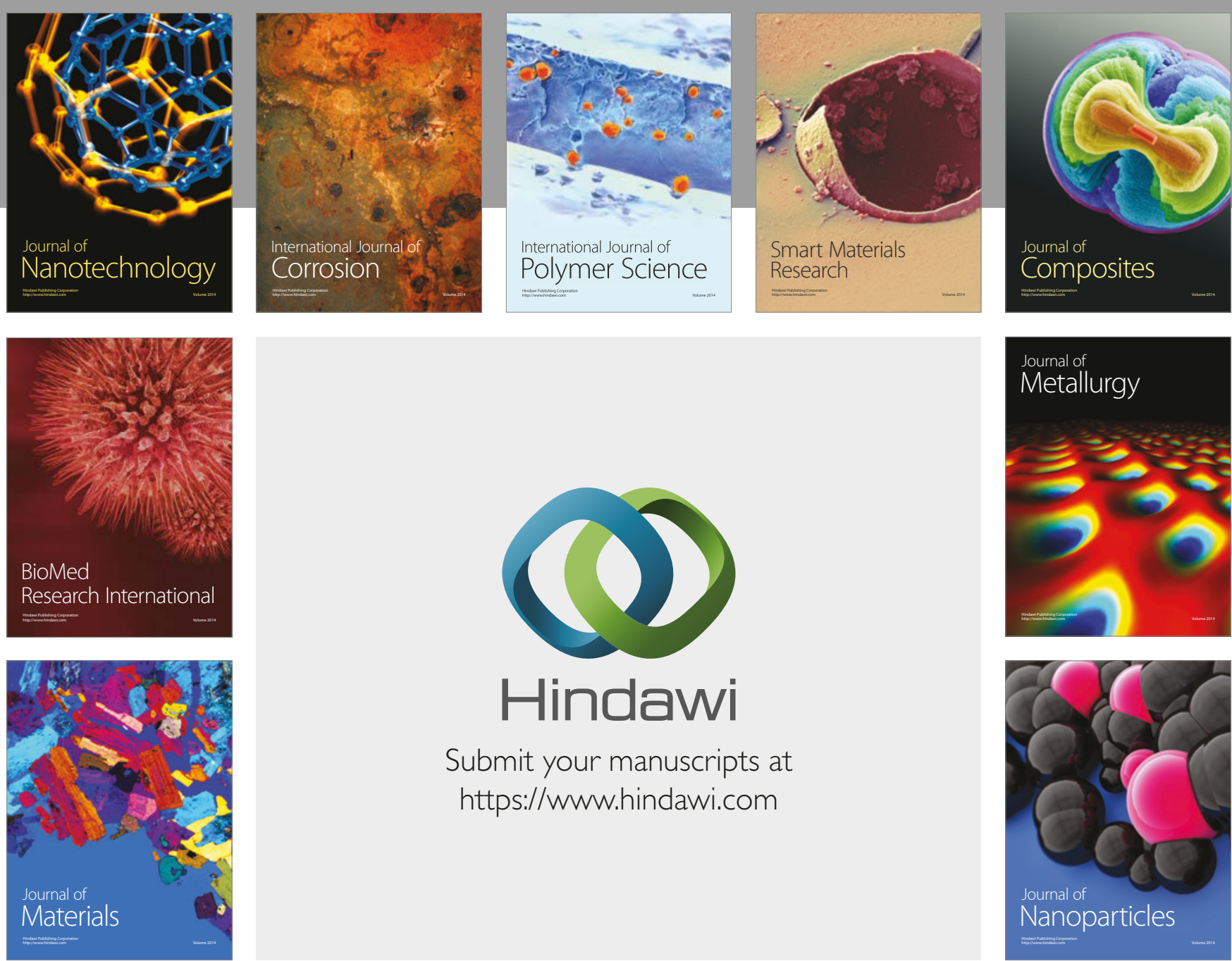

\section{Hindawi}

Submit your manuscripts at

https://www.hindawi.com
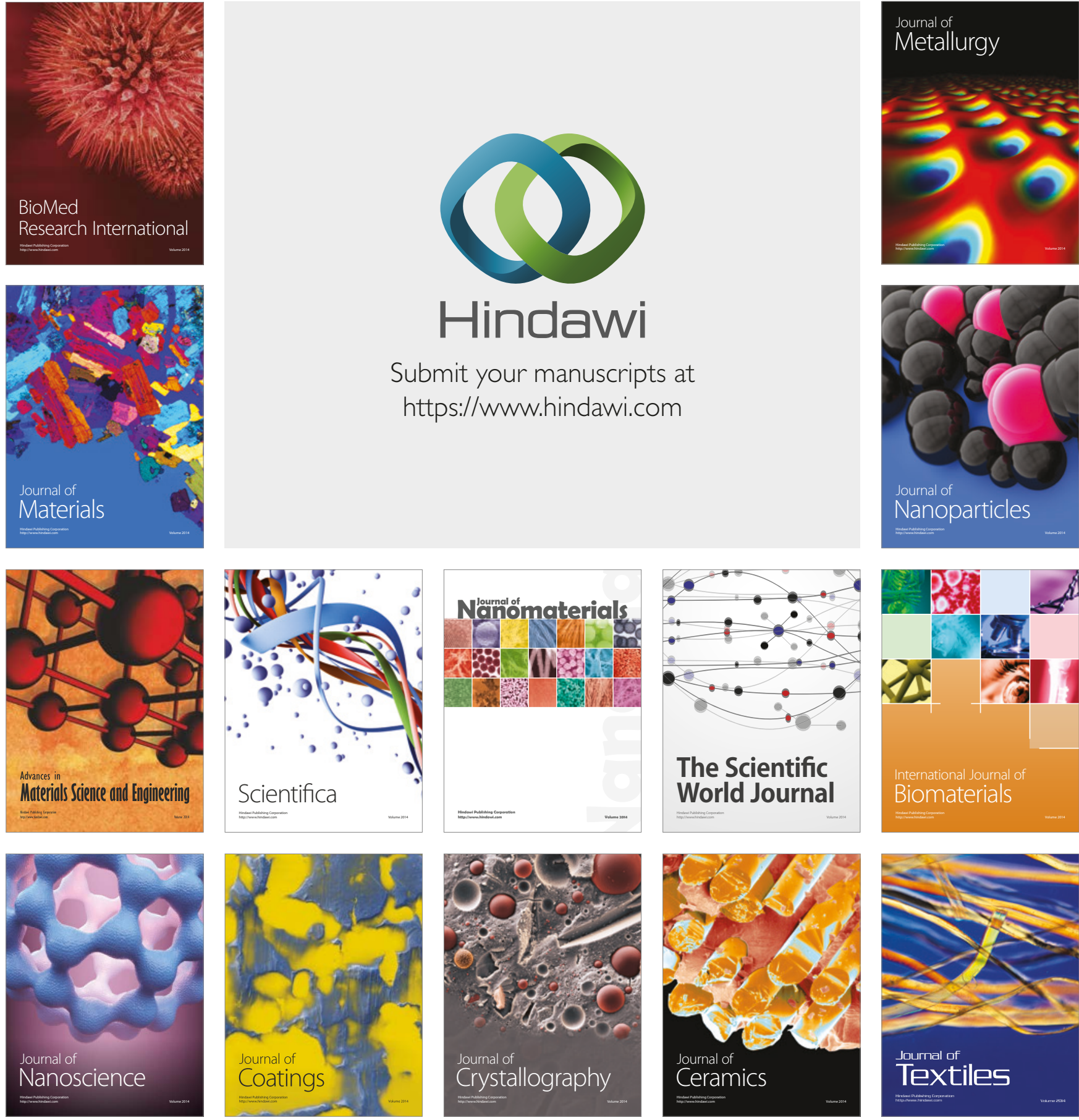

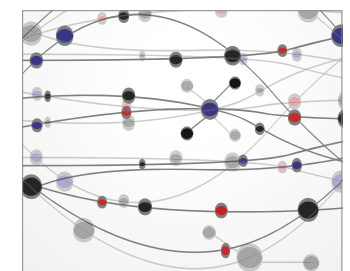

The Scientific World Journal
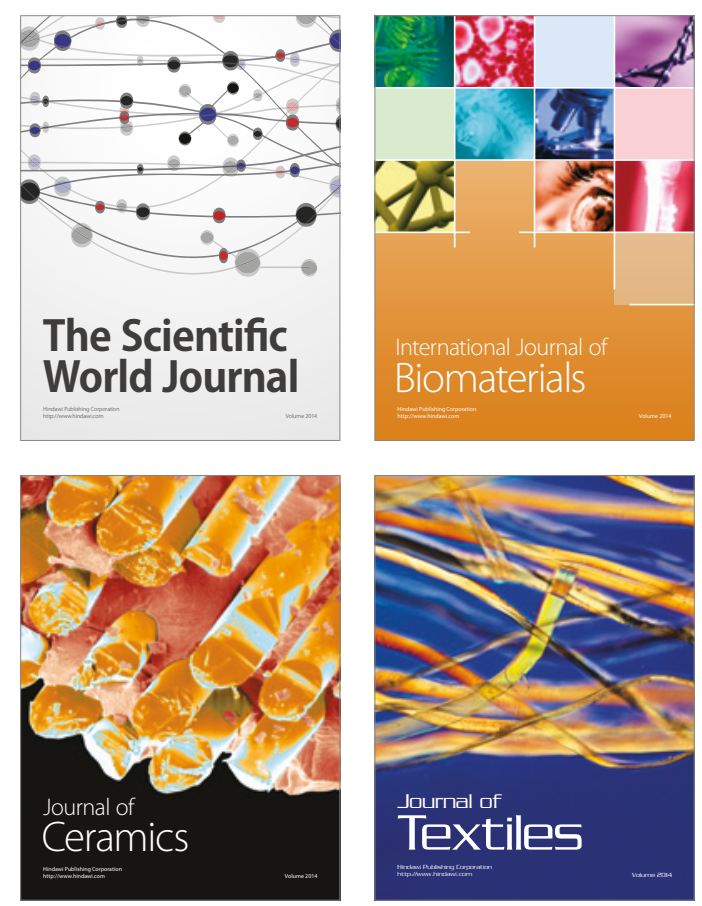